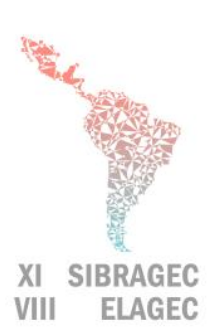

\section{SIMPÓSIO BRASILEIRO DE GESTÃO E ECONOMIA DA CONSTRUÇÃO \\ VIII ENCUENTRO LATINOAMERICANO DE GESTIÓN Y ECONOMÍA DE LA CONSTRUCCIÓN}

Do conhecimento à ação: práticas avançadas de gestão da produção Londrina, Paraná, Brasil. 23 a 25 de Outubro de 2019

\title{
ESTUDO DAS JURISPRUDÊNCIAS RELACIONADAS À NORMA DE DESEMPENHO
}

\author{
ROHR, Dener (1); COSTELLA, Marcelo Fabiano. (2); COSTELLA, Monike de \\ Medeiros (3)
}

(1) Unochapecó, denerohr@unochapeco.edu.br, (2) Unochapecó, costella@unochapeco.edu.br, (3) Unochapecó,monike@unochapeco.edu.br

\begin{abstract}
The purpose of this article is to analyze the jurisprudence related to the performance standard to expose the current understanding of the Brazilian judiciary regarding compliance with the standard NBR 15575 in the maintenance, warranty, and useful life. The research method consisted of the collection of jurisprudence in the Jusbrasil website that covered the courts of the second and third instance civil courts of all Brazilian states between 2013 and 2018 through the keywords "nbr 15575", "nbr 15.575" and" performance standard." Among the 19 analyzed processes, the requirements of design life and water tightness to external moisture sources were the most frequent. Also, there was a trend of decisions favorable to the authors of disputes, represented by construction and real estate clients. Technical aspects of three processes are also discussed because of the peculiarity of the decision. The contribution of the research is based on the observation of court issues, supported by NBR 15575 to present the primary deficiencies of the projects, providing measures to combat them and reduce possible legal proceedings.
\end{abstract}

Keywords: Performance standard. NBR 15575. Jurisprudence. Construction.

\section{INTRODUÇÃ̃O}

A NBR 15575, segundo a Câmara Brasileira da Indústria da Construção (CBIC) (2013, p. 6), “[...] constitui importante e indispensável marco para a modernização tecnológica da construção brasileira e melhoria da qualidade de nossas habitações.”. Com ela foi possível definir parâmetros, objetivos e quantitativos para o desempenho dos elementos e sistemas construtivos (COSTELLA, 2018), um conjunto de elementos da construção que associados e coordenados formam um todo lógico, empregados nas edificações habitacionais brasileiras (BENTO et al., 2016).

Mesmo após a normatização tem sido comum os casos em que os consumidores apresentam insatisfação em relação ao próprio imóvel quanto à qualidade dos serviços prestados pela construtora. $\mathrm{O}$ aumento da percepção do consumidor no que se refere à qualidade da construção intensifica a busca na justiça pelos prejuízos sofridos. Em função disso, os resultados dessas ações servem de parâmetro para as atuais interpretações como indicativos para a tomada de decisões dos casos semelhantes (DEL MAR, 2016). Nesse sentido, as jurisprudências são o conjunto das decisões e interpretações das leis feitas pelos tribunais superiores, adaptando as normas às situações de fato. Segundo Del Mar (2007), a finalidade da jurisprudência é firmar um posicionamento sobre determinado tema para que sirva de fundamento a outros casos semelhantes. 
Com base nisso esta pesquisa observa as questões que incidem em tribunais tendo como respaldo a NBR 15575 (ABNT, 2013a,b,c,d,e,f) para apresentar as principais deficiências dos empreendimentos, prevendo medidas para combatê-las e diminuir os possíveis processos judiciais. Os estudos jurisprudenciais são comuns na área de Direito, porém pouco comuns na Engenharia, por isso não foram identificados trabalhos similares ou anteriores. Além disso, o estudo contemplou os primeiros processos após a vigência da norma de desempenho, pois apesar de estar vigorando desde 2013, demorou alguns anos para que as primeiras obras pós-norma fossem entregues e gerassem processos.

Assim, o objetivo desse artigo foi analisar as jurisprudências relacionadas à norma de desempenho com vistas a expor o atual entendimento do judiciário brasileiro quanto ao cumprimento da norma NBR 15575 (ABNT, 2013a,b,c,d,e,f) nos quesitos de manutenção, garantia, vida útil e prazos de responsabilidade.

\section{PROCEDIMENTOS METODOLÓGICOS}

\subsection{Definição da amostra}

A pesquisa documental teve como base o levantamento de dados e análise de jurisprudências da construção que tiveram como fundamento ou foram influenciadas pelas NBR 15575 em todo o Brasil. Foram considerados os processos publicados entre os anos de 2013 a 2018.

\subsection{Obtenção das amostras}

Os processos foram obtidos por meio do site Jusbrasil $^{1}$ e abrangeu os tribunais da justiça comum de segunda e terceira instância todos os estados brasileiros aplicando a seleção por meio das palavras-chaves "nbr 15575", "nbr 15.575" e "norma de desempenho".

Em seguida, realizou-se uma pré-seleção dos processos para identificar a relação com edificações habitacionais e se havia citação à norma de desempenho. Os processos que mencionaram a NBR 15575 e não estavam relacionados a edificações habitacionais foram contabilizados, porém não foram analisados.

\subsection{Análise das amostras}

Diante do exposto, os processos selecionados foram analisados buscando os quais continham referências aos itens da norma e se o caso em questão estava dentro da vigência da norma técnica, a qual se aplica a empreendimentos protocolados a partir de 19/07/2013. Nas jurisprudências a identidade das pessoas físicas foram ocultadas. Em relação às pessoas jurídicas, foram apresentadas apenas a natureza das operações. As entidades governamentais foram mantidas, por conta da natureza pública de suas ações.

Posteriormente, os processos foram sintetizados quanto aos seguintes critérios: das alegações das partes envolvidas, dos argumentos utilizados por advogados, das decisões dos magistrados e das citações aos itens da norma. Depois, comparou-se a incidência dos processos de cada estado (UF), com o item da norma e a tendência das decisões.

Por fim, foram destacados três processos para análise detalhada, sendo dois em que foram detectados erros na análise técnica da norma de desempenho e outro sobre o desempenho

\footnotetext{
${ }^{1}$ https://www.jusbrasil.com.br 
SIBRAGEC - ELAGEC 2019 - de 23 a 25 de Outubro - LONDRINA - PR

acústico, o qual, segundo Del Mar (2016), apresenta um grande potencial em termos de indenização.

\section{RESULTADOS}

\subsection{Análise Global das Jurisprudências}

A partir da coleta de dados foram encontradas 162 jurisprudências, entretanto somente 19 jurisprudências estão relacionadas com a norma de desempenho, as quais são apresentadas no Quadro 1 conforme a natureza do processo, estado de origem (UF), o ano de publicação (Publ.), o requisito da NBR 15575 e o agente favorecido.

\section{Quadro 1 - Análise Global das Jurisprudências}

\begin{tabular}{|c|c|c|c|c|c|}
\hline \# & UF & Publ. & Natureza & Requisito & Favorável à \\
\hline \multicolumn{6}{|c|}{ Resultados selecionados na busca por "nbr 15575" } \\
\hline \multirow{2}{*}{1} & \multicolumn{5}{|c|}{ Processo $n^{\circ} 02479620140$} \\
\hline & Nac. & 2015 & Não respeitadas dimensões mínimas. & 16.2 & Autor \\
\hline \multirow[b]{2}{*}{2} & \multicolumn{5}{|c|}{ Processo $n^{\circ} 0058993-18.2010 .8 .07 .0001$} \\
\hline & $\mathrm{DF}$ & 2017 & $\begin{array}{l}\text { Vida útil do projeto de revestimento cerâmico em pisos } \\
\text { internos inferir a norma. }\end{array}$ & $14.2,10.2$ & Autor \\
\hline 3 & \multicolumn{5}{|c|}{ Processo $n^{\circ} 5007335-95.2013 .404 .7205 / S C$} \\
\hline 3 & SC & 2016 & Impermeabilização inadequada. & 10.2 & Autor \\
\hline \multirow[b]{2}{*}{4} & \multicolumn{5}{|c|}{ Processo $n^{\circ} 1012685-52.2016 .8 .26 .0037$} \\
\hline & SP & 2017 & $\begin{array}{l}\text { Estanqueidade da impermeabilização e trincas em } \\
\text { janelas. }\end{array}$ & $14.2,10.2,7.2$ & Autor \\
\hline \multirow[b]{2}{*}{5} & \multicolumn{5}{|c|}{ Processo $n^{\circ} 1010702-86.2014 .8 .26 .0037$} \\
\hline & SP & 2016 & $\begin{array}{l}\text { Impermeabilização da viga baldrame, pintura } \\
\text { descascando, microfissuras no reboco e recalque na } \\
\text { rampa de acesso. }\end{array}$ & $10.2,14.2$ & Autor \\
\hline \multirow[b]{2}{*}{6} & \multicolumn{5}{|c|}{ Processo $n^{\circ} 2013.049874-8$} \\
\hline & $\mathrm{SC}$ & 2014 & $\begin{array}{l}\text { Casa de madeira. Danos provocadas por vibrações de } \\
\text { construção vizinha. Ausência de manutenção. Vida útil } \\
\text { de projeto de estruturas de madeira. }\end{array}$ & 14.2 & Réu \\
\hline \multirow[b]{2}{*}{7} & \multicolumn{5}{|c|}{${\text { Processo } n^{\circ} 0001642-14.2015 .8 .07 .0001}^{2}$} \\
\hline & DF & 2017 & $\begin{array}{l}\text { Face externa de porta externa inchada pela umidade das } \\
\text { intempéries. }\end{array}$ & 10.1 (Parte 4) & Autor \\
\hline 8 & \multicolumn{5}{|c|}{ Processo $n^{\circ} 1.616 .070-2$ PR } \\
\hline 8 & PR & 2017 & Destelhamento e Infiltração e danos ao forro de gesso. & 14.2 & Autor \\
\hline 9 & \multicolumn{5}{|c|}{ Processo $n^{\circ} 1.514 .738-9$ PR } \\
\hline 9 & PR & 2016 & Queda de forramento de gesso da sala de estar. & 14.2 & Autor \\
\hline \multirow[b]{2}{*}{10} & \multicolumn{5}{|c|}{ Processo $n^{\circ} 0015081-71.2005 .8 .24 .0033$} \\
\hline & SC & 2018 & $\begin{array}{l}\text { Erros no projeto e execução de obra. Risco de } \\
\text { desmoronamento. }\end{array}$ & 14.2 & Réu \\
\hline \multirow[b]{2}{*}{11} & \multicolumn{5}{|c|}{ Processo $n^{\circ} 038.295 / 2012-1$} \\
\hline & $\mathrm{PB}$ & 2017 & $\begin{array}{l}\text { Utilização de blocos cerâmicos de vedação em } \\
\text { alvenaria com função estrutural. Falhas na análise do } \\
\text { projeto e na fiscalização da obra. Fissuração com } \\
\text { posterior infiltração. }\end{array}$ & $\begin{array}{l}14.2,7.2,7.3 \\
\text { (Parte 1) e } 7.2 \\
\quad \text { (Parte } 4)\end{array}$ & Autor \\
\hline 12 & \multicolumn{5}{|c|}{ Processo no $5008739-50.2014 .404 .7205 / S C$} \\
\hline 12 & $\mathrm{SC}$ & 2016 & Alagamento e retorno de esgoto. Falta de manutenção. & 14.3 .1 & Autor \\
\hline \multirow[b]{2}{*}{13} & \multicolumn{5}{|c|}{ Processo $n^{\circ} 1027489-64.2014 .8 .26 .0564$} \\
\hline & SP & 2018 & Níveis altos de ruídos dentro do imóvel. & $\begin{array}{l}12.3 .2 \text { (Parte } 3) \\
\text { e } 12.3 \text { (Parte 5) }\end{array}$ & Réu \\
\hline \multirow[b]{2}{*}{14} & \multicolumn{5}{|c|}{${\text { Processo } n^{\circ} 0006280-27.2009 .8 .26 .0404}^{1}$} \\
\hline & SP & 2017 & $\begin{array}{l}\text { Danos causados pela falta de manutenção e ampliação } \\
\text { sem orientação técnica. }\end{array}$ & 14.3 .1 & Réu \\
\hline 15 & Proce & sso $n^{\circ}$ & $1002989-25.2014 .8 .26 .0566$ & & \\
\hline 15 & SP & 2015 & Pé-direito mínimo não respeitado. & 16.1 & Autor \\
\hline & Proce & $\operatorname{sson} n^{\circ}$ & $1031351-05.2016 .8 .26 .0554$ & & \\
\hline 16 & SP & 2018 & $\begin{array}{l}\text { Vazamento de adutora de água causa danos a uma casa } \\
\text { sem impermeabilização. }\end{array}$ & 10.2 & Autor \\
\hline & & & Resultados selecionados na busca por "nbr & 15.575" & \\
\hline & Proce & sso $n^{\circ}$ & $0025409-17.2010 .8 .26 .0005$ & & \\
\hline 17 & $\mathrm{SP}$ & 2014 & $\begin{array}{l}\text { Infiltração, trincas e fissuras e pé-direito mínimo não } \\
\text { respeitado. }\end{array}$ & 10.2 e 16.1 & Autor \\
\hline & & & Resultados selecionados na busca por "norma de & desempenho" & \\
\hline & Proce & so $n^{\circ}$ & 5022706-32.2013.4.04.7001/PR & & \\
\hline 18 & PR & 2017 & $\begin{array}{l}\text { Suportes utilizados para fixação da pia da cozinha não } \\
\text { eram adequados às cargas estipuladas por norma. }\end{array}$ & 9.2 & Autor \\
\hline & Proce & sso $n^{\circ}$ & $0045044-82.2012 .8 .26 .0564$ & & \\
\hline 19 & SP & 2016 & $\begin{array}{l}\text { Pintura interna desgastada e diversos defeitos } \\
\text { construtivos. }\end{array}$ & 14.2 & Autor \\
\hline
\end{tabular}

Fonte: elaborado pelos autores 
SIBRAGEC - ELAGEC 2019 - de 23 a 25 de Outubro - LONDRINA - PR

\subsection{Análise das Incidências nas jurisprudências}

Entre os 19 processos selecionados a maioria dos itens citados pertencia à Parte 1 da norma, que aborda os requisitos gerais, conforme o Quadro 2.

Quadro 2 - Lista dos itens da norma de desempenho citados nas jurisprudências

\begin{tabular}{|l|l|}
\hline Item & Título \\
\hline 14.2 & Requisito - Vida útil de projeto do edifício e dos sistemas que o compõem \\
\hline 10.2 & Requisito - Estanqueidade a fontes de umidade externas à edificação \\
\hline 14.3 .1 & Requisito - Manutenibilidade do edifício e de seus sistemas \\
\hline 7.2 & Requisito - Estabilidade e resistência estrutural \\
\hline $\begin{array}{l}10.1 \\
(15575-4)\end{array}$ & $\begin{array}{l}\text { Requisito - Infiltração de água nos sistemas de vedações verticais externas } \\
\text { fachadas) }\end{array}$ \\
\hline $\begin{array}{l}12.3 \\
(15575-5)\end{array}$ & Requisito - Isolamento acústico da cobertura devido a sons aéreos \\
\hline $\begin{array}{l}12.3 .2 \\
(15575-3)\end{array}$ & $\begin{array}{l}\text { Requisito - Isolamento de ruído aéreo dos sistemas de pisos entre unidades } \\
\text { habitacionais }\end{array}$ \\
\hline 16.1 & Requisito - Altura mínima de pé direito \\
\hline 16.2 & Requisito - Disponibilidade mínima de espaços para uso e operação da habitação \\
\hline $\begin{array}{l}7.2 \\
(15575-4)\end{array}$ & $\begin{array}{l}\text { Requisito - Deslocamentos, fissuração e ocorrência de falhas nos sistemas de } \\
\text { vedações verticais internas e externas }\end{array}$ \\
\hline 7.3 & Requisito - Deformações, fissurações ocorrência de outras falhas \\
\hline 9.2 & Requisito - Segurança na utilização do imóvel \\
\hline E.7.2.4 & Nível de desempenho - Níveis de pressão sonora contínuo equivalente, LAeq,nT \\
\hline E.7.2.5 & Nível de desempenho - Níveis de pressão sonora máximo, LASmax,nT \\
\hline
\end{tabular}

Fonte: elaborado pelos autores

A maior incidência do item 14.2 pode ser explicada pelo fato de muitos processos citarem a durabilidade dos materiais e sistemas construtivos, comparando o tempo de utilização (vida útil) com o tempo esperado de utilização (vida útil de projeto - VUP), o qual é estimado nas Tabelas 14.1, C.5 e C.6 da NBR 15575-1 (ABNT, 2013a). Ainda nesse sentido foi possível observar que a categoria Durabilidade e manutenibilidade possui a maior parcela dos 30 itens citados (Figura 1).

Figura 1 - Incidência por categoria de desempenho

9. Segurança no uso e na operação

16. Funcionalidade e acessibilidade

12. Desempenho acústico

7. Desempenho estrutural

10. Estanqueidade

14. Durabilidade e manutenibilidade
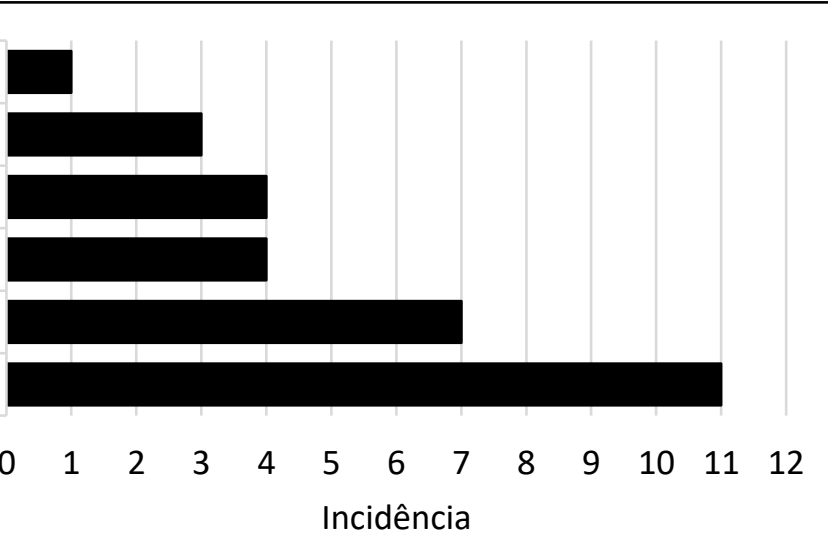

Fonte: elaborado pelos autores 


\section{SIBRAGEC - ELAGEC 2019 - de 23 a 25 de Outubro - LONDRINA - PR}

Em relação ao estado da Federação, foi possível constatar que os estados de São Paulo e Santa Catarina possuem o maior número de processos, estando em primeiro e segundo lugares com, respectivamente, $42 \%$ e $21 \%$ dos processos.

Quanto às decisões proferidas pelos magistrados, observou-se que 79\% das decisões foram favoráveis aos autores das ações, em sua maioria, clientes de construtoras ou imobiliárias, enquanto que $21 \%$ foram a favor dos réus, representados por construtoras, imobiliárias ou agentes financeiros.

\subsection{Discussão das jurisprudências}

O requisito de desempenho da NBR 15575 mais citado nos processos foi o de Vida Útil de Projeto - VUP, sendo mencionado em nove entre os 19 processos analisados. Tal requisito serviu como base para os advogados construírem seus argumentos nas questões envolvendo vícios construtivos e demais problemas percebidos pelos clientes. Esses argumentos comparavam a vida útil alcançada pelo bem com a vida útil projetada que, em muitos casos, não foi atingida, e o principal motivo foi a ineficiência das manutenções preventivas ou a ausência delas. Outro ponto crítico nessas jurisprudências foi de que, apesar do Art. $26^{\circ}$ do CDC estabelecer que a responsabilidade pelos vícios ocultos possui um prazo prescricional preconizado no Art. $27^{\circ}$ do CDC, este não tem sido observado e a responsabilidade vem sendo atribuída às construtoras e imobiliárias, mesmo que já tenha ultrapassado esse prazo ou qualquer outra garantia contratual.

$\mathrm{O}$ segundo requisito mais citado foi "estanqueidade a fontes de umidades externas à edificação", estando presente em seis jurisprudências, as quais se referiam a manchas oriundas de umidade ascendente. $\mathrm{Na}$ descrição do processo foi observado que o descumprimento em relação à NBR 15575 se referia à falta de projeto ou de medidas que evitassem a infiltração da água de chuva e da umidade do solo nessas habitações. Tal exigência da norma serve para estimular que esse tipo de serviço tenha como base especificações técnicas no projeto, já que é de difícil correção.

No processo $\mathrm{n}^{\mathrm{o}}$ 5008739-50.2014.404.7205/SC, relacionado a vícios construtivos que propiciavam o refluxo de esgoto e alagamentos em unidade residencial, uma vez que uma das caixas de inspeção da rede de esgoto/pluvial fora construída com altura incorreta. A decisão foi favorável à reclamante e as empresas reclamadas foram condenadas ao pagamento de danos morais e reparação no imóvel. Contudo, uma das empresas reclamadas alegou, em suas considerações técnicas acerca do laudo pericial, que a limpeza semestral das caixas de inspeção não estava sendo realizada. No entanto, tais ações de manutenção devem ser especificadas pelo projetista ou construtor no Manual de Uso, Manutenção e Operação de acordo com a NBR 14037 (ABNT, 2011). Porém, não foi possível identificar no texto do processo se este manual foi ou não fornecido ao usuário e, portanto, também não é possível afirmar se ele foi ou não devidamente cumprido. Entretanto, se houvesse essa indicação de manutenção no Manual de Uso, Manutenção e Operação e ela não tivesse sido cumprida, a tendência seria de responsabilização do réu, nesse caso.

O processo $\mathrm{n}^{\mathrm{o}}$ 1027489-64.2014.8.26.0564, iniciado no ano de 2014, no qual, apesar do não cumprimento aos requisitos de desempenho acústico dispostos na NBR 15575 (ABNT, 2013a,c,d,e), a empresa construtora foi considerada isenta de responsabilidade pois, no momento da entrega do imóvel e do respectivo habite-se, em maio de 2011, a norma de desempenho não estava em vigor. Nesse caso, se a edificação tivesse sido executada a partir da vigência da norma teria havido a responsabilização da construtora 
e, provavelmente, geraria um "efeito cascata" de reclamações dos demais moradores da edificação.

No processo $\mathrm{n}^{\circ}$ 0045044-82.2012.8.26.0564 foi observada uma menção a prazo de durabilidade, referente ao requisito "14.2 Requisito - Vida útil de projeto..." da NBR 15575. Nesse processo houve uma confusão entre os conceitos de "nível de desempenho superior" e "imóvel padrão superior", no qual o primeiro é um balizador do nível de desempenho que é possível ser tecnicamente obtido, destacando uma forma de minimizar os custos de manutenção e operação através de uma VUP mais elevada e indutor para que o mercado busque soluções com melhor custo-benefício, além das que já atendem a VUP mínima. Enquanto o segundo refere-se ao padrão construtivo estabelecido pela NBR 12721 para aferição do custo da edificação, não necessariamente tratando da durabilidade dos materiais e técnicas empregadas. Em função disso, houve uma afirmação incorreta de que o prazo de durabilidade da pintura interna para imóveis de padrão superior (uma vez que a VUP deve ser estipulada pelo projetista e registrada em projeto, porém se não for declarada será considerada como desempenho mínimo) seria de 4 anos. Nesse caso a indicação da norma de desempenho para a VUP da pintura interna é de 3 anos, essa diferença provocou a responsabilização da construtora.

\section{CONCLUSÕES}

Este artigo buscou levantar e discutir as primeiras jurisprudências ligadas à norma de desempenho de modo a entender o posicionamento do judiciário quanto à aplicação dos conceitos da norma. Foi possível identificar um foco de discussão no quesito de vida útil de projeto, no qual foi identificado uma falta de conhecimento técnico que ocasionaram alguns erros técnicos nos processos. Isso demonstra a importância da qualificação dos profissionais de engenharia para dar suporte aos advogados nesse tipo de processo e viceversa. Já uma fonte de preocupação do mercado imobiliário, que são reclamações acerca do desempenho acústico, apareceram em somente um processo.

A discussão de vida útil de projeto e prazos de responsabilidade tende a ser aumentada e continuada visto que esse estudo encontrou poucas jurisprudências em função da limitação de busca de processos somente em segunda e terceira instância, as quais levam um longo tempo de tramitação. Portanto, novos trabalhos podem replicar esse estudo com objetivo de acompanhamento dos processos que atualmente estão em tramitação em primeira instância.

\section{REFERÊNCIAS}

ABNT - ASSOCIAÇÃO BRASILEIRA DE NORMAS TÉCNICAS. NBR 14037: Diretrizes para elaboração de uso, operação e manutenção das edificações - Requisitos para elaboração e apresentação dos conteúdos. Rio de Janeiro, 2011.

ABNT - ASSOCIAÇÃO BRASILEIRA DE NORMAS TÉCNICAS. NBR 15575-1: Norma de Desempenho em Edificações Habitacionais: Requisitos gerais. Rio de Janeiro, 2013a.

ABNT - ASSOCIAÇÃO BRASILEIRA DE NORMAS TÉCNICAS. NBR 15575-2: Norma de Desempenho em Edificações Habitacionais: Requisitos para os sistemas estruturais. Rio de Janeiro, 2013b.

ABNT - ASSOCIAÇÃO BRASILEIRA DE NORMAS TÉCNICAS. NBR 15575-3: Norma de Desempenho em Edificações Habitacionais: Requisitos para os sistemas de pisos. Rio de Janeiro, 2013c. 
SIBRAGEC - ELAGEC 2019 - de 23 a 25 de Outubro - LONDRINA - PR

ABNT - ASSOCIAÇÃO BRASILEIRA DE NORMAS TÉCNICAS. NBR 15575-4: Norma de Desempenho em Edificações Habitacionais: Sistemas de vedações verticais internas e externas SVVIE. Rio de Janeiro, 2013d.

ABNT - ASSOCIAÇÃO BRASILEIRA DE NORMAS TÉCNICAS. NBR 15575-5: Norma de Desempenho em Edificações Habitacionais: Requisitos para sistemas de coberturas. Rio de Janeiro, 2013e.

ABNT - ASSOCIAÇÃO BRASILEIRA DE NORMAS TÉCNICAS. NBR 15575-6: Norma de Desempenho em Edificações Habitacionais: Sistemas Hidrossanitários. Rio de Janeiro, $2013 \mathrm{f}$.

BENTO, A.; NEVES, D.; PIRES, J.; OLIVEIRA, M.; SILVA; D. A influência da NBR 15575 (2013) na durabilidade e vida útil das edificações residenciais. In: SEMINÁRIO DE

PATOLOGIA E RECUPERAÇÃO ESTRUTURAL, 1, 2016, Recife, PE. Anais [...]. Recife, 2016.

CBIC - CÂMARA BRASILEIRA DA INDÚSTRIA DA CONSTRUÇÃO. Guia orientativo para atendimento à norma ABNT NBR 15575/2013. 2 ed. Brasília, 2013. Disponível em: <http://www.cbic.org.br/arquivos/guia_livro/Guia_CBIC_Norma_Desempenho.pdf $>$. Acesso em: 12 set. 2017.

COSTELLA, Marcelo Fabiano. Norma de desempenho de edificações: Modelo de aplicação em construtoras. 1 ed. Curitiba: Appris, 2018.

DEL MAR, C. P. Falhas, Responsabilidades e Garantias na Construção Civil. São Paulo: PINI, 2007. $366 \mathrm{p}$.

DEL MAR, C. P. Normalização e Normas Técnicas / Desempenho e Vida Útil / Garantias e Responsabilidades - (panorama jurídico). In: CONSTRUMETAL 2016. São Paulo, 20-22 set. 2016. Disponível em: < http://www.abcem.org.br/construmetal/downloads/apresentacoes2017/apresentacao-carlos-del-mar-2016.pdf>. Acesso em: 1 mar. 2018. 